\title{
Corpus interactivo para el tratamiento integrado de letras musicales en sílabos gramaticales
}

\author{
Francisco Garrido Molina. Universidad de Granada
}

Recepción: 30/06/2018 | Aceptado: 17/04/2019

Correspondencia a través de ORCID: Francisco Garrido Molina

iD 0000-0001-6753-6721

Citar: Garrido Molina, F (2019). Corpus interactivo para el tratamiento integrado de letras musicales en sílabos gramaticales. ReiDoCrea - Monográfico sobre Perspectivas transnacionales en la enseñanza de lenguas, 8(3), 109-127.

Resumen: En el presente trabajo pretendemos dar cuenta del desarrollo de una herramienta que, a partir de un corpus amplio analizado y etiquetado, facilite el uso selectivo de canciones para el tratamiento en la clase de ELE de recursos gramaticales distintos. Pretendemos configurar una base de datos que proporcione información sobre las opciones disponibles para la práctica de los diferentes recursos lingüísticos que interesen al profesor. Con un corpus interactivo como el que pretendemos confeccionar, en el que las canciones serán descritas en relación a variables lingüísticas, pero también otras de carácter temático, el profesor de ELE podrá aprovechar el potencial didáctico de la música de forma sistemática y adecuada eligiendo para cada ocasión entre una gama variada según gustos, intereses o necesidades. La base de datos que se desarrollará podrá servir de punto de partida para posibles aplicaciones desarrollables para ordenadores o dispositivos móviles como "smartphones" y tableta, los cuales podrán ser usadas a discreción tanto por profesores como por alumnos.

Palabras clave: Enseñanza de idiomas | Música

Interactive corpus focused on music lyrics within grammar syllabi

\begin{abstract}
In this paper we intend to describe the development of a corpus-based tool, which analyses and labels music lyrics for its use in SSL classroom in concern about grammar lessons. We try to set a data base that allows teachers and students to access the many options that music offers to teach and learn a language. With an interactive corpus as we are trying to develop, in which songs will be described in relation with linguistic and thematic criteria, the SSL teacher will be able to use the potential in music as a teaching tool in a systematic way. The choice of a song could be based on a wide variety of tastes, genres, interests and linguistic needs. This data base will be adequate as a starting point for a future development of desktop or mobile devices application for students and teachers to use.
\end{abstract}

Keywords: Language instruction | Music

\section{Introducción}

El siguiente estudio pretende aportar un elemento de mejora al uso de las canciones en el aula de ELE en particular, y en la enseñanza de segundas lenguas en general, dado que la herramienta es aplicable a otras lenguas.

Intentamos mejorar uno de los aspectos importantes que hay que considerar a la hora de llevar canciones al aula: la decisión de qué canción elegir. En el proceso de selección el docente se enfrenta a varias cuestiones. En primer lugar, la relativa a los aspectos que tienen que ver con las características propiamente musicales de la canción. Esto es, por ejemplo, a qué estilo musical y época se adscribe la canción y qué implica cada una de estas variables. Además, la letra de la canción puede ser, o no, adecuada al nivel que nos interesa, por lo que será otro aspecto que deberá analizar el docente antes de decidirse. Por último, y esto es un aspecto bastante interesante de este proceso, habría que preguntarse: ¿qué canciones querrán escuchar mis alumnos?, ¿qué canción funcionará mejor? Por supuesto, todo dependerá de cada caso concreto y de qué peso quiere darle el docente a cada uno de los aspectos mencionados. 
Podemos afirmar, por lo tanto, que se trata de algo complejo. Llevar a cabo la elección de la canción que se quiere usar en la clase requiere de un esfuerzo por parte del docente, incluso previo al diseño de la tarea y previo al desarrollo de esta en el aula.

Teniendo en cuenta todo lo expuesto, creemos que es muy importante explorar propuestas y desarrollar herramientas que faciliten el trabajo del docente a la hora de elegir la canción que se integre adecuadamente en el programa que sigue y en los contenidos que aborda en cada parte del mismo.

En relación con ello, el objetivo principal de este trabajo ha consistido en el diseño de una herramienta informática que facilite la búsqueda y selección de canciones adecuadas a los distintos contenidos docentes, a los diferentes contextos escolares y los variados perfiles de estudiantes que pueden necesitar de estos recursos. La herramienta consiste en una hoja de cálculo que permite el acceso sistematizado a una base de datos constituida por canciones de géneros muy variados. La idea es que los docentes cuenten con un corpus de letras de canciones ya analizadas desde el punto de vista gramatical y sociocultural. Esto, además de facilitar su tarea, fomentaría una mayor variedad en la música que se trata en las clases de ELE y, por tanto, una mayor capacidad de adaptación a los distintos intereses y necesidades de los estudiantes y el profesor.

\section{Objetivos}

El objetivo principal de este trabajo ha consistido en el diseño de una herramienta informática que facilite la búsqueda y selección de canciones adecuadas a los distintos contenidos docentes, a los diferentes contextos escolares y los variados perfiles de estudiantes que pueden necesitar de estos recursos. La herramienta consiste en una hoja de cálculo que permite el acceso sistematizado a una base de datos constituida por canciones de géneros muy variados. La idea es que los docentes cuenten con un corpus de letras de canciones ya analizadas desde el punto de vista gramatical y sociocultural. Esto, además de facilitar su tarea, fomentaría una mayor variedad en la música que se trata en las clases de ELE y, por tanto, una mayor capacidad de adaptación a los distintos intereses y necesidades de los estudiantes y el profesor.

\section{Marco teórico}

\section{El impacto de las canciones como recurso didáctico}

La música ha sido un elemento presente en la enseñanza de lenguas desde hace ya mucho tiempo. Esto se debe a que se puede entender una canción como un elemento de múltiples posibilidades dentro del aula.

Para empezar, la música tiene una fuerte relación con el discurso oral. Besson y Chobert (2013) establecen un paralelismo entre la música y el habla mostrando sus elementos en común. Señalan que las dos se basan en señales auditivas complejas con los mismos parámetros: frecuencia, duración, intensidad y timbre, y apuntan que comparten la característica de organizarse en múltiples niveles. En el caso de la música, el ritmo, la melodía y la armonía, que en lengua corresponderían a los diferentes niveles lingüísticos.

Existe asimismo una relación entre la música y la adquisición de la lengua materna por parte de los niños. García y Sáenz (2015) afirman que «en la adquisición de la lengua materna, los niños usan los aspectos musicales del idioma (ritmo, timbre, melodía) como andamiaje para el posterior desarrollo de los aspectos sintácticos y semánticos de la lengua». (p. 385).

De la misma manera, afirman que «los niños, por ejemplo, son capaces de retener grandes cantidades de información gracias a la música, el ritmo o la rima, debido a la 
activación de partes del cerebro ligadas a la emoción, la memoria y el lenguaje». (García y Sáenz, 2015, p. 386).

La música favorece la motivación y el proceso de enseñanza/aprendizaje al posibilitar la combinación de diferentes estilos de aprendizaje. (García y Sáenz, 2015), (Fernández Martín, 2013), (Coronado y García, 1994).

Además, atiende a casi todos los tipos de inteligencia. (Prieto,2017, p.133), (Rodríguez López, 2005, p.806).

La música está en todas partes, forma parte de nuestra vida, tiene la capacidad de hacernos sentir identificados. En el aula, favorece un ambiente desinhibido y relajado. (Jiménez et. al, 2009), (Murphey, 1992 p.7). También es una muestra real de la cultura meta, que puede servir para trabajar aspectos culturales. (Coronado y García, 1994 p. 227).

Fernández Martín (2013) considera que esto ayuda a mejorar la implicación del alumno. Según ella, existe una fuerte relación entre:

(...) las ganas que un alumno tenga por aprender un idioma y su actitud hacia la sociedad en que se habla, fomentada en ocasiones por algunos productos culturales que haya recibido (y percibido) como interesantes. (...) Es en este punto donde la música puede desempeñar un papel mediador entre la representación que de la sociedad de asentamiento se puede forjar de nuevas en el alumno y la representación previa que de ella antes tenía según una fusión en que se incluyen las normas socioculturales de su propio país de origen y la experiencia vivida. (p.10)

El hecho de que las canciones sean vehículos de la cultura meta, también hace que puedan ser «desencadenantes de debates sobre cuestiones polémicas en la clase y como reflejo social y lingüístico de las variedades del español y los países en los que se habla». (Rodríguez, 2005, p.807).

Para que el uso de las canciones en la clase dé buenos resultados, Heras, Sáez y Serrano (2015) afirman que hay que atender a la «adecuación de géneros y épocas musicales a los destinatarios concretos, (...) el interés mostrado hacia las canciones puede permitir avances (...) sobre todo si se llegan a interiorizar sus estructuras como consecuencia de la recreación y la memoria». (p.1135).

Con estos argumentos y opiniones recabadas de diferentes autores, queda demostrado el impacto positivo de la música en el aula de ELE. Sin embargo, hay también algunos aspectos que provocan que los profesores descarten el uso de este material o le otorguen un papel secundario.

Las opiniones más frecuentes son que ni los profesores ni alumnos se toman en serio el uso de música, la creencia de que usar este material hace perder el tiempo y apartarse del sílabo que se esté trabajando, la dificultad para idear una explotación correcta y con unos objetivos claros de este recurso y, de nuevo, la dificultad a la hora de elegir las canciones. (Murphey, 1992, p.8).

Rodríguez López (2005) entiende la elección como una posible desventaja si el docente comete un error a la hora de elegir el material: «(...) todo el componente motivador que puede suponer una canción para un alumno puede potencialmente representar lo contrario para otro al que no le gusta un determinado tipo de música, intérprete o grupo». (p.808).

García y Sáenz (2015) aportan evidencias de que hay algunos géneros que sí escuchan los alumnos y que son ignorados por los materiales. 
Por lo tanto, en aras de fomentar la motivación, consideramos que es importante revertir esta situación y facilitar el acceso de los alumnos a una mayor variedad en cuanto a géneros musicales.

\section{Lingüística de corpus aplicada a la enseñanza de lenguas}

La idea de combinar la lingüística de corpus y la enseñanza de idiomas lleva ya tiempo presente entre los especialistas de ambos campos. Sus aplicaciones parecen cada vez más interesantes y existen estudios que demuestran su utilidad en varios aspectos de la enseñanza de segundas lenguas.

Alonso Pérez-Ávila (2007), habla de lo interesante de entender el corpus como una fuente provechosa de input y para elaborar materiales. Pensando en el enfoque de la gramática inductiva, afirma: "Una vez que el aprendiente recibe el input puede comenzar a elaborar hipótesis sobre las estructuras y las reglas gramaticales de la L2; dichas hipótesis se verificarán o rechazarán mediante la recepción de más input». (p.1617).

También alude a otros enfoques dentro de la lingüística, como son la lingüística cognitiva y el enfoque léxico, ya que los corpus lingüísticos tienen la ventaja de ofrecer muestras reales de lengua en su contexto. Esto permite al aprendiente ver qué palabras suelen aparecer combinadas entre ellas y aprender lo que se ha venido a denominar chunks, otra manera de ver el aprendizaje de vocabulario. (Alonso Pérez-Ávila, 2007, p.17).

En cuanto a la lingüística cognitiva, entiende que el corpus favorece la enseñanza integrada, dado que «las búsquedas de concordancias las unidades léxicas aparecen contextualizadas y «se puede trabajar de forma simultánea el léxico y la pragmática». (Alonso Pérez-Ávila, 2007, p.21-22).

Entiende, asimismo, que el corpus favorece la enseñanza dentro del enfoque comunicativo refiriéndose al uso de lenguaje significativo, la autonomía del estudiante, la atención tanto a la forma como al significado. (Alonso Pérez- Ávila, 2007).

Recski (2006) considera que la posibilidad de acceder a un corpus y descubrir las palabras más comunes en ciertos contextos, podría suplir el hecho de no estar en inmersión.

Además, sugiere que cuando los profesores hacen generalizaciones sobre reglas gramaticales para facilitar su comprensión por parte de los alumnos, a veces pueden cometerse errores o sencillamente dejar de lado algunos usos que debieran tenerse en cuenta. Lo explica de la siguiente manera:

El problema es si las reglas y generalizaciones capturan efectivamente cómo la lengua se usa en realidad en vez de describir como se debería usar, y si estas reglas reflejan los patrones de uso más comunes. El acceso (...) corpus permite a los profesores revisar reglas prescriptivas y generalizaciones que no concuerdan con los datos lingüísticos (...) (Recski, 2006) [Traducción propia]

López García (2013) entiende que los corpus son «modelos orales de gran valor para conocer desde un enfoque pragmático las producciones reales de los hablantes de una comunidad lingüística determinada». (p.397).

En su caso, tras aplicar textos extraídos del corpus COGILA en la clase de español como lengua extranjera de nivel intermedio, afirma: «(...) los alumnos (...) han manifestado en todo momento su gran disposición para enfrentarse a este reto lingüístico en su formación y al finalizar las tareas nos han transmitido su satisfacción por el dominio de contenidos inusuales y por haber mejorado su grado de comprensión auditiva en la interacción con hablantes nativos». (López García, 2013, p.407). 
En definitiva, quedan pocas dudas sobre el efecto positivo del uso de corpus en el proceso de E/A. No obstante, existen algunos problemas y dificultades que quedan por solucionar. No todos los profesores y alumnos saben manejar corpus, y este proceso puede hacerse complicado para ambas partes.

\section{Descripción de la herramienta}

En este trabajo hemos elaborado una herramienta que intenta solucionar los problemas comentados en las secciones anteriores sobre la búsqueda, identificación y selección de canciones para su integración en los programas de enseñanza de ELE y mejorar o complementar los instrumentos o recursos ya disponibles en el ámbito de ELE.

En primer lugar, va más allá de la recogida de letras y su traducción. Las letras estarán analizadas según descriptores gramaticales. Concretamente, se tendrá en cuenta el sistema verbal. Además, como hacen las aplicaciones de música en streaming, clasificará las canciones según su género, autor y época.

También aportará información sobre el nivel adecuado para trabajar con cada canción. Esto es complicado, ya que muchas veces el nivel dependerá más la explotación que del material en sí. No obstante, se incluye una etiqueta de nivel para canción. En el caso de las canciones que ya se encuentran junto a su propuesta didáctica en Todoele o MarcoEle, se ha tomado el nivel de esas propuestas. La diferencia es que en lugar de usar los niveles del MCERL de $A 1$ a $C 2$, he tomado la división menos específica de inicial (A1-2), intermedio (B1-2) y avanzado (C1-2). Para el resto de las canciones fue un poco más complicado, dado que no se trata solo de que aparezca cierto tiempo verbal, sino que hay que tomar en cuenta el uso y el contexto en el que aparece. No obstante, entre niveles inicial, intermedio y avanzado hay algunas divisiones claras. Para esto se ha tenido en cuenta el Plan Curricular del Instituto Cervantes. El subjuntivo es el descriptor más claro para discernir entre una canción de nivel inicial e intermedio, ya que este modo verbal aparece en el PCIC por primera vez en el nivel B1. En el B2 se introduce casi todo el resto de los tiempos del subjuntivo, y en el nivel avanzado se ven tiempos como el futuro perfecto de subjuntivo.

Además, no solo se aplicarán descriptores gramaticales, sino que también se incluirá información sobre el contenido sociocultural de una canción, en el caso de que esta represente especialmente algún aspecto de este tipo.

En segundo lugar, y debido precisamente a lo que acabamos de indicar, la herramienta facilita el proceso de selección del material, con todas las variantes que hemos visto hasta ahora. Tanto profesores como alumnos tendrán una herramienta que facilite el acuerdo sobre qué canciones usar en el aula.

De cualquier manera, una herramienta de estas características facilitaría el proceso de selección independientemente de que el docente quiera llevar a cabo una negociación con los alumnos sobre el material usado en clase.

Asimismo, el recurso que plantemos aquí ayudaría a aportar variedad a las canciones explotadas en la clase. Tiene en cuenta géneros tan dispares como el pop y el flamenco, el rap o la música latina. El español es una lengua que nos ofrece esa oportunidad y quizá no la estemos aprovechando tanto como deberíamos.

Basta con tener una idea del tipo de canción que se quiera llevar al aula para que la herramienta proponga las posibilidades más útiles.

Existen implicaciones también desde el punto de vista del aprendizaje autónomo. En nuestra opinión, cuando un alumno de L2 entra en contacto con un producto cultural de la cultura meta, hay que procurar despertar su interés y fomentar su motivación. Contar 
con la posibilidad de acceder a un corpus analizado que muestre a la vez qué gramática va a aparecer en las letras y a qué género, autor y época pertenecen, aumenta la posibilidad de que se integre y se lleve este pedazo de cultura fuera del aula, añadiéndolo a su propia experiencia cultural.

Por lo tanto, esta herramienta no se limita al uso en el aula, sino que ofrece la posibilidad de que los estudiantes la usen de manera autónoma y expandan su potencial.

Por último, otro de los problemas a los que aluden algunos docentes sobre el uso de canciones es la dificultad para idear una explotación adecuada de este material. En este sentido, y como ya hemos señalado antes, la herramienta tendrá en cuenta las listas de canciones que numerosos profesionales han compartido en las páginas web TodoEle y MarcoEle. Estas canciones ya se encuentran en la red junto a diferentes propuestas de explotación, las cuales también se encontrarán en la herramienta.

\section{En torno a la definición de la herramienta con relación a los corpus lingüísticos}

Sin ánimo de profundizar mucho en explicaciones teóricas sobre lingüística de corpus, tiene sentido situar esta propuesta en el marco de la aplicación de la lingüística de corpus a la E/A de ELE, y ello según las coordenadas que establece Alonso Pérez-Ávila. Lo cierto es que esta herramienta no es un corpus al uso, pero sí que teniendo en cuenta las definiciones que da esta autora, comparte con ellas lo esencial.

La autora cita a McCullough y su definición: «un corpus de textos es un conjunto de documentos que una persona o una organización ha reunido y ha informatizado para un fin determinado». (Alonso Pérez-Ávila, 2007, p.12).

También añade la definición de EAGLES (Expert Advisory Group on Language Engineering) que define un corpus como «una colección de muestras de lengua que se han seleccionado tomando en cuenta criterios lingüísticos explícitos para ser usados como ejemplos de una lengua». (Alonso Pérez-Ávila, 2007, p.13). [Traducción propia]

Coincide en gran medida con la última definición que aporta la propia Pérez, que caracteriza un corpus de la siguiente manera: «un conjunto de textos informatizados producidos en situaciones reales, que se han seleccionado siguiendo una serie de criterios lingüísticos explícitos que garantizan que dicho corpus pueda ser usado como muestra representativa de la lengua». (Alonso Pérez-Ávila, 2007, p.13).

Estas definiciones, como ya hemos indicado, no son las únicas que se proponen desde los autores dedicados a esta disciplina, pero sí que son las que nos permiten identificar esta herramienta como un corpus. En primer lugar, es una colección de textos informatizados. Además, sigue un etiquetado que tiene en cuenta criterios lingüísticos explícitos (el sistema verbal), y busca ofrecer muestras reales de lengua (en este caso, dentro del contexto de un texto de carácter literario o artístico, como hiciera un corpus de literatura).

No obstante, hay aspectos que esta herramienta no comparte con los corpus al uso y que la alejan de estos. Los textos no se encuentran informatizados usando un programa específicamente pensado para el corpus lingüístico y, además, no trata concordancias.

Debido a las razones aducidas, tenemos razones a favor y en contra de dar a nuestra herramienta el nombre de "corpus», así que convendremos en definirla como un corpus, pero no al uso, al menos en la fase en la que se encuentra por el momento.

En lo que sigue, se describen detalladamente las características y funciones de nuestra propuesta y se ofrece una explicación de cómo se ha desarrollado hasta ahora. 
Paradójicamente, para empezar a describir el potencial de la herramienta hay que hablar de algunas limitaciones. De entrada, no ha sido posible la colaboración con ningún técnico especialista en programación que facilitase el desarrollo de la aplicación apropiada para usar en diferentes dispositivos. Además de esto, se hizo evidente al principio de trabajar en este proyecto, que la limitación temporal iba a hacer muy difícil el dominio y el uso de las herramientas existentes para la creación de corpus. No solo por la dedicación necesaria para dominar los programas en sí, sino por todo lo requerido para armar la herramienta con las funcionalidades que hemos explicado a partir de las opciones que cada programa ofrece.

Por esta razón, hemos optado por una solución más eficiente que muestra con simplicidad la idea del corpus y que es fácil de usar. Es una opción que nos atreveríamos a calificar de austera y, en principio, poco técnica, en el sentido de que no usa, como ya hemos visto, convenciones relativas a los corpus lingüísticos de hoy en día.

Hemos elegido, por lo tanto, un programa de procesamiento de datos más accesible y sencillo de usar, como es el procesador de hojas de cálculo Excel. Su simplicidad es precisamente su principal ventaja.

Al no usar ningún programa ideado para el etiquetado de textos, este proceso se ha llevado a cabo manualmente. Hay un total de ciento ochenta y nueve canciones analizadas. A continuación, se describe el proceso que se ha llevado a cabo y los elementos que constituyen la estructura del recurso.

\section{Filtros}

La elección de canciones según diferentes filtros está en la base de la idea de esta herramienta. Como hacen numerosas aplicaciones de música en streaming, el usuario tiene la posibilidad de seleccionar los filtros que quiere para buscar en la base de datos de canciones. Una parte de estos filtros los comparte con cualquier aplicación de música. Se trata de filtros que permiten elegir el género, la época, y si se quiere, buscar el autor de la canción. El resto de los filtros que se incluyen, son todos los tiempos verbales del sistema verbal.

\section{Etiquetado de las canciones}

El propósito de analizar el sistema verbal en las canciones es el de ofrecer recomendaciones de canciones que tienen unas ocurrencias significativas de esos verbos. Como hemos dicho, hay ciento ochenta y nueve canciones analizadas en la herramienta. Es más que probable que exista más de una canción que coincida con las características que el usuario escoja. Es decir, si, por ejemplo, buscamos una canción de rock alternativo, de la presente década y que contenga presente de indicativo, la herramienta nos recomendará varias que según la base de datos coinciden con esos filtros. Sin embargo, no todas esas canciones tendrán el mismo número de ocurrencias de presente de indicativo. Es más, puede que una tenga un alto número de ocurrencias de presente de indicativo pero que todas esas ocurrencias sean de un mismo verbo, persona y número; mientras que otra, muestre más variedad léxica o diferentes personas y número. Por lo tanto, nos pareció necesario que la herramienta tuviera esto en cuenta y transmitiese esta información al usuario.

La repetición, como hemos visto en el marco teórico es un elemento clave en las letras de las canciones y un elemento que juega a favor de la memorización de estructuras lingüísticas. Pero también es posible que el docente busque un material que reúna una cierta variedad de un tiempo verbal para que los alumnos adquieran nuevo vocabulario, o se familiaricen de esta manera con un mismo tiempo verbal, pero con verbos de 
diferentes conjugaciones, 0 incluso que muestre verbos regulares junto a verbos irregulares. En definitiva, tanto variedad como repetición pueden ser interesantes en combinación y por separado. Esto planteó un problema que hizo necesaria una reflexión sobre el etiquetado de las canciones. No sería suficiente con indicar que una letra contiene ciertos tiempos verbales, pero a partir de ahí, hubo que decidir si era mejor tener más en cuenta la variedad o la repetición.

Para esto, es útil la distinción entre tipo y ocurrencia (muchas veces se encuentran estos conceptos en inglés, como type y token). En cuanto al sistema verbal, entenderemos token como cualquier ocurrencia de un tiempo verbal, sin importar de qué verbo, persona o número sea. Si alguna de esas tres variables cambia, la unidad léxica se entiende como tipo. Por ejemplo, si en una canción aparece tres veces la palabra "escuché», y una vez "escuchaste» y "escuchamos», contaríamos cinco ocurrencias y tres tipos.

Por lo tanto, se optó por contar solamente los tipos y hacer un cálculo en el que, dentro de la combinación de filtros, se toma en cuenta el número máximo de tipos que puede tener una canción y se calcula qué porcentaje de esa cantidad obtiene cada canción. A mayor promedio de porcentajes y a mayor representatividad de dicho promedio, la canción aparecerá antes en la lista, de esta manera el usuario sabrá qué letras ofrecen más variedad, pero tendrá a la vista todas las demás opciones. Esto se hace para asegurarse de que todas las canciones que antes se proponen tengan tipos de todos los filtros seleccionados. Si simplemente se sumaran los porcentajes, es probable que una canción con un gran número de tipos de cierto verbo y ninguno de otro, obtuviera más puntuación que una que ofreciera más equilibrio.

\section{Género y época}

Como ya hemos explicado, uno de los objetivos específicos de este trabajo es tratar de aportar variedad a las canciones que se trabajan en el aula. Por esta razón, se ha prestado mucha atención a los géneros y las épocas de las canciones, intentando no perder esa idea de variedad.

En cuanto a los géneros, hemos intentado ser todo lo inclusivos posible. La clasificación de géneros que se han incluido en la herramienta no tiene por qué ser la mejor ni tampoco la definitiva, en el caso de que la herramienta siga desarrollándose.

Hemos ido añadiendo géneros, en muchos de los casos, según las canciones añadidas lo requerían. No obstante, es complicado acertar con precisión a la hora de definir el género de una canción. Muchas veces, los géneros no se diferencian con claridad los unos de los otros. A veces un grupo se adscribe a un género por razones más socioculturales que por sus características musicales. En este sentido, una canción de El Kanka con ritmo, instrumentación y armonía de blues no será "blues" sino "cantautor", aunque no dejará de ser un blues. En el caso particular de los cantautores, esto ocurrirá no solo con el blues, sino con el reggae y hasta con el vals.

Hay casos en los que es aún más difícil discernir. Este puede ser el caso de la música latina, que puede ser pop y tener elementos de salsa o merengue. De la misma manera hay cantantes latinoamericanos de música alternativa que se atreven con ritmos tradicionales y los llevan al terreno de la música alternativa. Por último, y quizás aquí esté lo más complicado, tenemos el rock y todas sus ramas y sus fusiones. De esta manera, la herramienta tiene un gran número de géneros musicales. Son los siguientes: flamenco, alt-rock, baladas, bolero, cantautor, electrolatin, electrónica, flamenco-rock, folk, funk, fusión, indie, indie-pop, indie-rock, latin, latin-afrobeat, latin-alt, latin-salsa, pop, pop-fusión, pop-latin, pop-rock, ranch-rock, ranchera, rap, reggae, reggae-alt, rock, 
rock'n'roll, rumba, rumbarock, ska y tango. Como puede verse, hay varias combinaciones de diferentes géneros, y las hojas de Excel están preparadas para mostrar géneros parecidos en el caso de que no exista ninguna coincidencia de unos filtros y géneros en concreto. Es decir, si el usuario elije pop-rock y subjuntivo, y no existe ninguna canción con esa combinación de etiquetas, al menos aparecerán canciones que tengan subjuntivo y sean rock, o pop.

Aunque esto no sea un aspecto esencial de una herramienta destinada a la enseñanza de ELE, cuanto mejor se vean reflejados los géneros en las opciones, mejor trabajarán los usuarios.

En lo que a época se refiere, hemos optado por hacer una división por décadas. No obstante, ocurre algo parecido a lo que ocurre con los géneros. Las fronteras cronológicas entre épocas no coinciden a veces con movimientos culturales que se adhieren a una década en concreto. De esta manera, se ha optado por un funcionamiento parecido al de los géneros musicales. Si no existen en la herramienta canciones con los filtros deseados y de una época en concreto, mostrará canciones de la década anterior y posterior. Las décadas que recoge van desde los años cuarenta hasta hoy en día. Se ha incluido un periodo tan largo de tiempo, sencillamente por el hecho de tener la opción de etiquetar una canción en cualquiera época. A pesar de esto, en la práctica la gran mayoría se encuentran en los noventa, dos mil y la década presente.

\section{Partes}

Como ya hemos visto, la herramienta se ha desarrollado sobre un documento Excel, un documento con varias hojas de cálculo que se comunican entre ellas y que funcionan como si de una página web se tratase. Parece evidente que, si bien el manejo es sencillo, la idea no podría desarrollarse sin superar este modelo. Se trata más bien del desarrollo del modelo que sirva de pauta, en cuanto a configuración de datos y acceso a los mismos, a aplicaciones posteriores que permitan acceder a la misma estructura de datos en una interacción usario/herrameinta más versátil y amigable.

El documento tiene siete hojas de cálculo diferentes que se comunican entre ellas con fórmulas matemáticas. Se han nombrado las hojas con los siguientes nombres: interfaz, letras, base de datos, selección, RELgénero, RELépoca y puntos (ver figura 1). Veremos primero qué son cada una de ellas para más tarde explicar cómo interactúan.

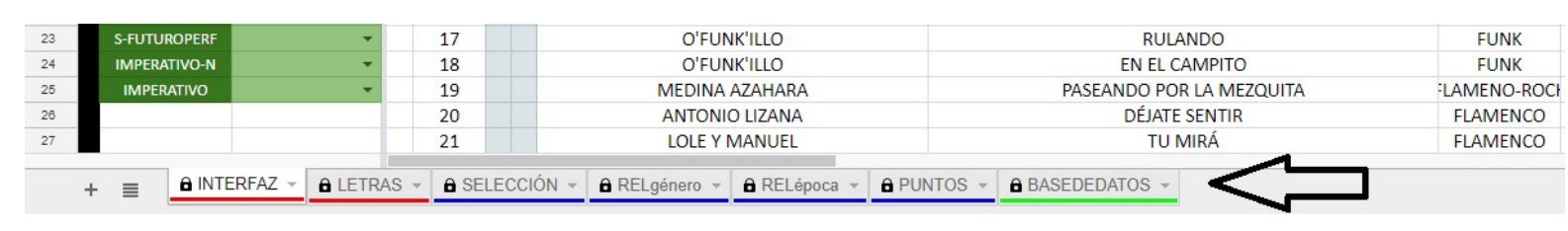

Fig. 1. Panel de las hojas del documento

\section{Interfaz}

La interfaz es la única hoja en la herramienta manipulable por los usuarios. Es lo que veríamos en la pantalla si se tratase de, por ejemplo, una aplicación móvil. En la interfaz es donde se encuentran los filtros que el usuario activará o desactivará según sus preferencias. Contiene un total de veintitrés filtros (ver figura 2). Los dos primeros son los que no tienen que ver con cuestiones gramaticales, lo que cualquier aplicación de música ofrecería, es decir, el género y la época. El resto corresponden al sistema verbal, todos los tiempos verbales de indicativo y subjuntivo, las formas impersonales más el imperativo y el imperativo negativo. Este último podría haberse adherido al presente de 
subjuntivo, pero consideramos más apropiado incluir un filtro de imperativo negativo que muestre no solo la forma, sino también el uso.

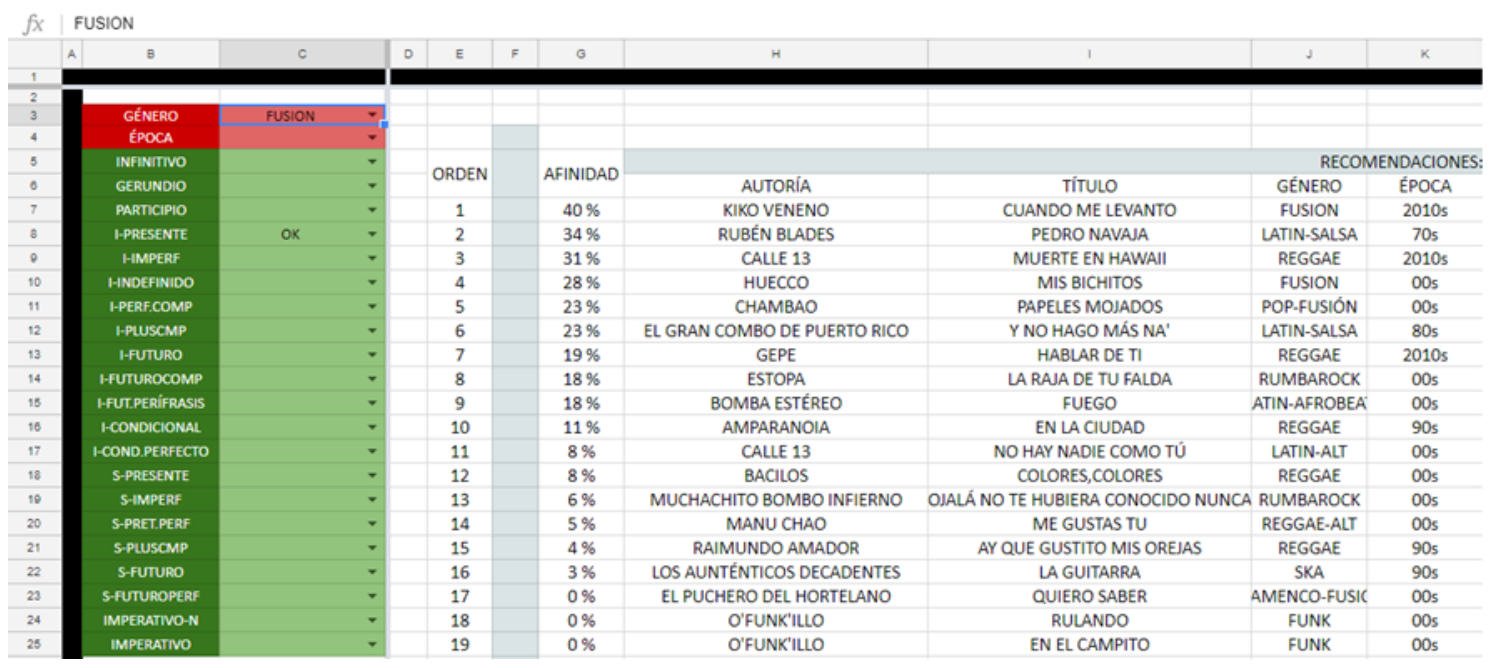

Fig. 2. Interfaz de la herramienta

Estos filtros se encuentran en dos columnas en la parte izquierda de la hoja de cálculo. La celda a la derecha de cada filtro es un desplegable que, al hacer click, muestra un "OK» (ver figura 3). Al seleccionar esto, se activará el tiempo verbal, y a la derecha, irán apareciendo las canciones que lo contienen.

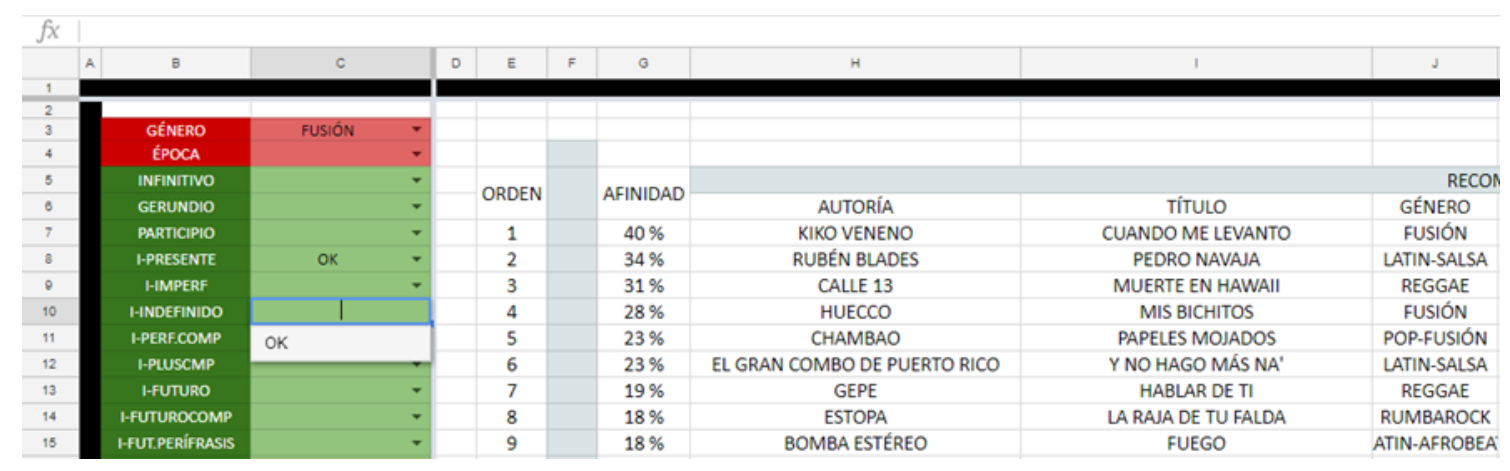

Fig. 3. Desplegable para seleccionar los filtros de tiempos verbales

Los dos filtros de género y época tienen una apariencia similar. El desplegable a la derecha, en este caso, muestra todas las opciones disponibles de épocas y géneros (ver figura 4).

De la misma manera, al seleccionarlos, a la derecha aparecerán las canciones que coinciden con la selección del usuario.

Estas canciones aparecen con toda la información. Las columnas de celdas son: orden, afinidad, autoría, título, género, época, explotación, nivel y contenido sociocultural. 


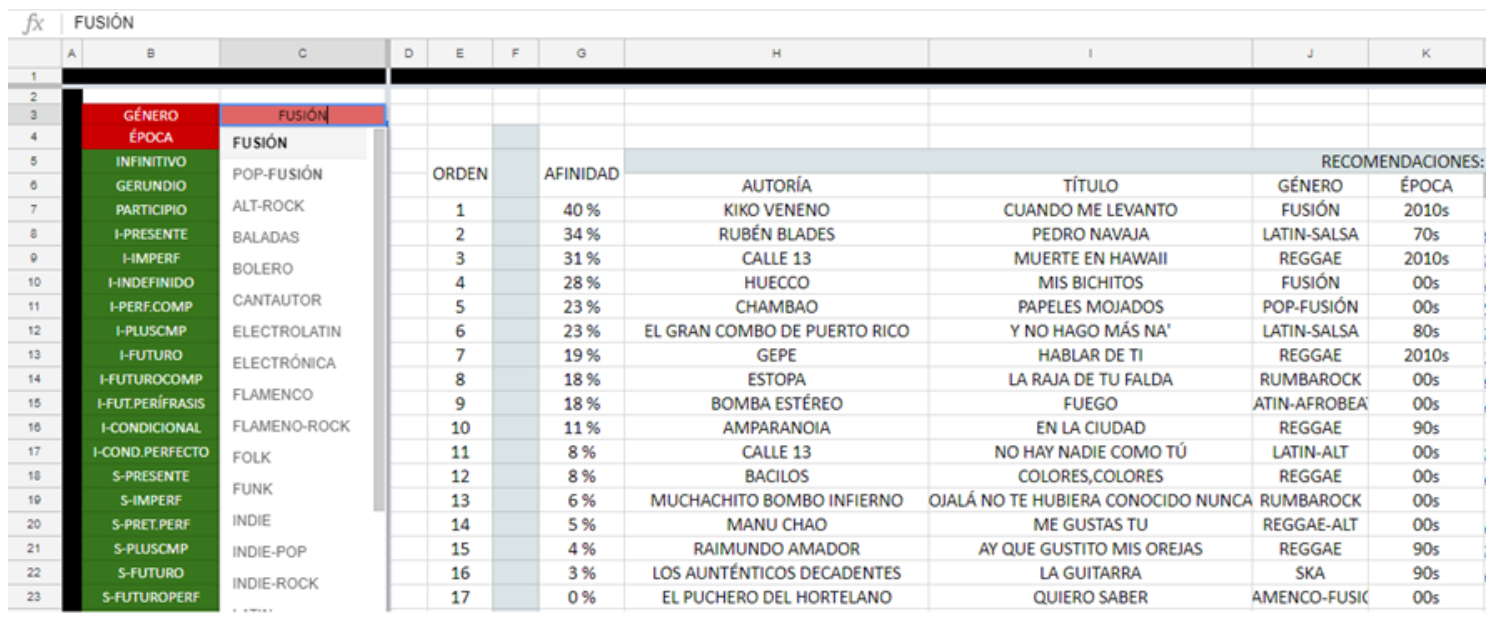

Fig. 4. Menú desplegable de los géneros

Las filas bajo la columna «orden» muestran un número correspondiente al orden en el que aparecen las canciones según su «afinidad», que no es más que el resultado, expresado en porcentaje, del cálculo que hemos explicado en el apartado de etiquetado de canciones y que veremos de nuevo en la hoja de puntos. Bajo la columna de "explotación" el usuario encontrará un hipervínculo que lo llevará al sitio web donde hallará una propuesta didáctica. Bajo la etiqueta «contenido sociocultural» el usuario podrá ver si la canción es especialmente significativa en relación con algún contenido sociocultural. Por ejemplo, aparecerá "crítica social" si la canción se caracteriza por esto o "rock andaluz" como fenómeno histórico y cultural.

Para tener una idea de cómo sería la apariencia de esta interfaz más pulida y en funcionando como una aplicación en un dispositivo como una tableta, se ha creado una propuesta de interfaz que puede verse en el anexo 1.

\section{Letras}

La hoja de letras contiene las letras de las canciones. Excel no está pensado como un procesador de texto, así que sencillamente, si el usuario quiere acceder inmediatamente a la letra de la canción, bastará con que entre en la hoja de letras, pulse «ctrl+f», escriba el nombre o el autor de la canción que quiere visualizar y el programa lo llevará automáticamente a las celdas en las que se han copiado las letras.

\section{Base de datos}

La base de datos contiene realmente toda la información esencial de la herramienta. Es donde están etiquetadas las canciones. Las columnas de la A3 a la AD3, llevan el título de cada filtro de los que hemos hablado. En las filas de abajo, está escrito el nombre, autor, género y época de las canciones. En las celdas de debajo de cada columna con la identificación de un tiempo verbal (por ejemplo, «S-PLUSCMP» para el pretérito pluscluamperfecto del subjuntivo) aparece el número de tipos de ese tiempo verbal que aparecen en la canción (ver figura 5). De aquí tomará el programa los datos con los que calcular si aparecen en la interfaz, o no, y en qué orden, las canciones de la base de datos. En el anexo 2 puede verse la base de datos con todas las etiquetas. 


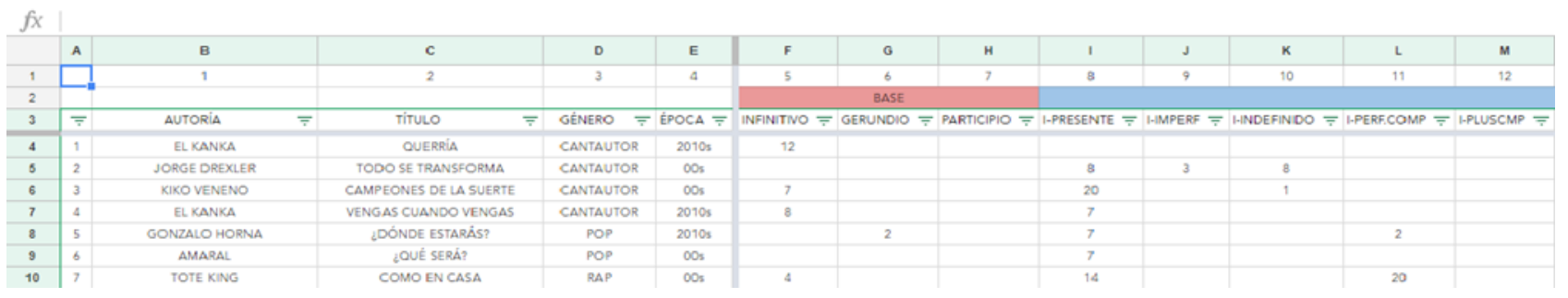

Fig. 5. Base de datos

\section{Selección, RELgénero y RELépoca}

Para que el programa haga que la interfaz y el resto de las hojas se comuniquen, es necesario «traducir», por decirlo de alguna manera, el lenguaje alfabético a un código alfanumérico de manera que el programa pueda «calcular», en lugar de leer. Estas tres hojas están dedicadas a esta traducción y funcionan para que, como hemos indicado anteriormente, si no hay una canción que coincida con nuestra búsqueda de género o época, el programa muestre opciones parecidas. La hoja de selección calcula y ordena por orden de preferencia, según lo que se haya seleccionado en la interfaz, los géneros y las épocas. Los datos para estos cálculos los toma de las hojas RELgénero y RELépoca, que establecen las relaciones. Por ejemplo, indie y rock, tienen cierta relación, mientras flamenco y reggae no tienen ninguna.

\section{Puntos}

Esta hoja es la que realmente hace que el documento funcione como una aplicación. La hoja de base de datos almacena la información, la interfaz establece los filtros para que el programa muestre las canciones que estamos buscando, y la hoja de puntos es la que calcula qué canciones van a aparecer.

Realmente es una tabla organizada de la misma manera que la hoja de base de datos, pero está dedicada a calcular qué canción es la más adecuada teniendo en cuenta los filtros que seleccionemos (ver figura 6).

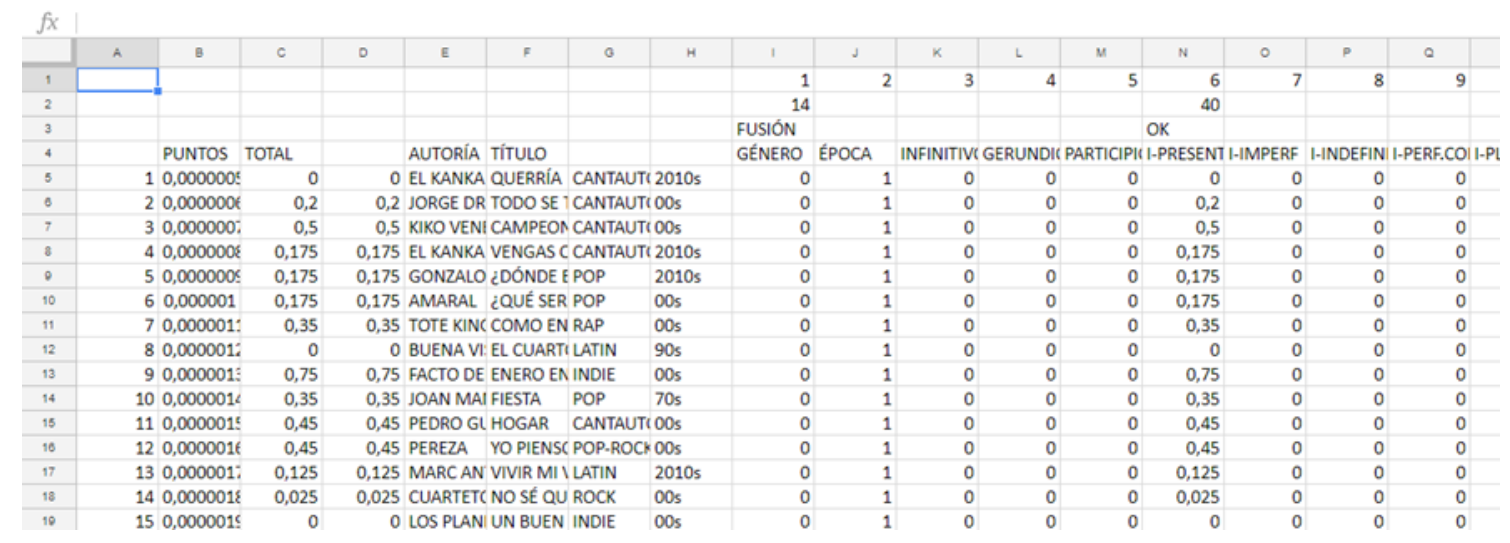

Fig. 6. Hoja de puntos

\section{Funcionamiento}

Aunque no es ni el tema ni el objetivo principal de este trabajo analizar de manera exhaustiva el funcionamiento interno de la herramienta, sí que es posible y necesario explicar cómo se seleccionan las canciones cuando se alteran los filtros, ya que el programa trabaja con las etiquetas lingüísticas que hemos comentado. 
El documento funciona con operadores lógicos y fórmulas matemáticas que hacen que las hojas se comuniquen entre ellas y que sea posible interactuar con él.

Cuando el usuario modifica cualquiera de los filtros en la interfaz, esta orden se transmite a la hoja de puntos, que cambia con cada combinación. Si, por ejemplo, en la interfaz se activa el presente de indicativo, también se activará en la hoja de puntos. Cuando se activa esa celda, el programa pone en funcionamiento una fórmula como la siguiente:

$$
\text { «=SI(N3="'";"';MAX(BASEDEDATOS!!4:I503)) » }
$$

En términos generales, esta fórmula viene a darle la orden al programa de que busque, en la base de datos, el valor máximo posible en la columna I, que en este caso es la que corresponde en la hoja de «BASE DE DATOS» al presente de indicativo. En la figura 7 podemos ver el aspecto de la hoja «PUNTOS» cuando está activado el filtro de presente de indicativo. Arriba aparece el número «40», esto quiere decir que el máximo valor posible con el que una canción está etiquetada es de cuarenta tipos de presente de indicativo. Esto nos sirve para hacer el cálculo que permite que las canciones aparezcan en la interfaz en el orden que queremos. Tomando en cuenta este valor máximo, se calcula la frecuencia relativa de cada canción según esa etiqueta gramatical. Estos valores aparecen en la casilla de presente de indicativo de cada canción. Esto quiere decir que, por cada etiqueta activa, cada canción puede puntuar un máximo de uno. Por ejemplo, la canción Campeones de la suerte de Kiko Veneno, tiene un «0,5» en la hoja de puntos en cuanto a presente de indicativo. Cuando hay más de un filtro activo, se calcula el promedio de las frecuencias para cada canción, y se combina numéricamente con un valor que asigna mayor puntuación si dicho promedio es más representativo, y la canción que más puntuación tenga aparecerá antes en la interfaz.

\begin{tabular}{|c|c|c|c|c|c|c|c|c|c|c|c|c|c|c|c|c|}
\hline$f x$ & $=\mathrm{SI}(\mathrm{N} 3=$ & " ; " "; $\operatorname{Max(B.}$ & BASEDEDATOS & $4: 1503)$ & & & & & & & & & & & & \\
\hline & A & 8 & c & D & E & $F$ & $\circ$ & H & 1 & J & k & L & M & N & $\circ$ & p \\
\hline 1 & & & & & & & & & 1 & 2 & 3 & 4 & 5 & 6 & 7 & 8 \\
\hline 2 & & & & & & & & & 14 & & & & & 40 & & \\
\hline 3 & & & & & & & & & FUSIÓN & & & & & OK & & \\
\hline 4 & & PUNTOS & TOTAL & & AUTORÍA & TÍtULO & & & GÉNERO & ÉPOCA & INFINITIVI C & GERUNDIC & PARTICIPIII & I-PRESENT I & I-IMPERF & I-INDEFIN \\
\hline 5 & 1 & $0,000000 \leqslant$ & 0 & 0 & EL KANKA & QUERRÍA & CANTAUTI & (2010s & 0 & $\begin{array}{l}1 \\
\end{array}$ & 0 & 0 & 0 & 0 & 0 & 0 \\
\hline - & 2 & $0,000000 t$ & 0,2 & 0,2 & JORGE DR & TODO SE 1 & CANTAUTS & $100 \mathrm{~s}$ & 0 & 1 & 0 & 0 & 0 & 0,2 & 0 & 0 \\
\hline 7 & 3 & 0,000000 & 0,5 & 0,5 & KIKO VENI & CAMPEON & CANTAUTS & $100 \mathrm{~s}$ & 0 & 1 & 0 & 0 & 0 & 0,5 & 0 & 0 \\
\hline 8 & 4 & 0,000000 & 0,175 & 0,175 & EL KANKA & VENGAS C & CANTAUTIC & (2010s & 0 & 1 & 0 & 0 & 0 & 0,175 & 0 & 0 \\
\hline 。 & 5 & 0,000000 & 0,175 & 0,175 & GONZALO & ¿DÓNDE E & POP & $2010 \mathrm{~s}$ & 0 & 1 & 0 & 0 & 0 & 0,175 & 0 & 0 \\
\hline 10 & 6 & 0,000001 & 0,175 & 0,175 & AMARAL & ¿QUÉ SER & POP & $00 \mathrm{~s}$ & 0 & 1 & 0 & 0 & 0 & 0,175 & 0 & 0 \\
\hline 11 & 7 & 0,000001 & 0,35 & 0,35 & TOTE KINC & COMO EN & RAP & 00s & 0 & 1 & 0 & 0 & 0 & 0,35 & 0 & 0 \\
\hline 12 & 8 & $0,000001:$ & 0 & 0 & BUENA VI: & EL CUARTIL & LATIN & 90s & 0 & 1 & 0 & 0 & 0 & 0 & 0 & 0 \\
\hline 13 & 9 & $0,000001:$ & 0,75 & 0,75 & FACTO DE & ENERO EN I & INDIE & 00 s & 0 & 1 & 0 & 0 & 0 & 0,75 & 0 & 0 \\
\hline 14 & 10 & 0,000001 & 0,35 & 0,35 . & JOAN MAI & FIESTA & POP & $70 \mathrm{~s}$ & 0 & 1 & 0 & 0 & 0 & 0,35 & 0 & 0 \\
\hline 15 & 11 & $0,000001:$ & 0,45 & 0,45 & PEDRO Gl & HOGAR & CANTAUTS & $100 \mathrm{~s}$ & 0 & 1 & 0 & 0 & 0 & 0,45 & 0 & 0 \\
\hline 16 & 12 & $0,000001 t$ & 0,45 & 0,45 & PEREZA & YO PIENSC & (POP-ROCK & $00 \mathrm{~s}$ & 0 & 1 & 0 & 0 & 0 & 0,45 & 0 & 0 \\
\hline 17 & 13 & 0,000001 & 0,125 & 0,125 & MARC AN & VIVIR MI IL & LATIN & $2010 \mathrm{~s}$ & 0 & 1 & 0 & 0 & 0 & 0,125 & 0 & 0 \\
\hline 18 & 14 & $0,000001 \varepsilon$ & 0,025 & 0,025 & CUARTETC & NO SÉ QU & ROCK & $00 \mathrm{~s}$ & 0 & 1 & 0 & 0 & 0 & 0,025 & 0 & 0 \\
\hline 10 & 15 & 0,000001 & 0 & 0 & LOS PLAN & UN BUEN I & INDIE & $00 \mathrm{~s}$ & 0 & 1 & 0 & 0 & 0 & 0 & 0 & 0 \\
\hline
\end{tabular}

Fig. 7. Hoja de puntos con los filtros "fusión" y "presente de indicativo" activos

Cuando la hoja de puntos hace los cálculos correspondientes, por una parte, al etiquetado en relación con el sistema verbal y, por otra parte, al género y al número, en la hoja de interfaz se aplican unas fórmulas que hacen que esta busque en la hoja de puntos las canciones correspondientes. Simplificándolo, la hoja de puntos toma y procesa información de la base de datos a partir de «órdenes» de la hoja de interfaz, y la hoja de interfaz muestra las canciones sirviéndose de información de la hoja de puntos. En la celda F7 se encuentra la siguiente fórmula:

$$
\text { «=SI(E7="'";"'; K.ESIMO.MAYOR(PUNTOS!\$B\$5:\$B \$504;E7))» }
$$

En resumen, lo importante de esta fórmula es la parte de «K.ESIMO.MAYOR», donde $\mathrm{K}$ puede ser cualquier número. En este caso, buscará en la hoja de puntos el número mayor que se encuentre en la columna donde aparecen los resultados del cálculo de la 
puntuación de cada canción según una combinación de filtros. Como «K» puede ser cualquier número, en la celda F8 buscará el segundo mayor, en la celda F9 el tercero mayor, y así sucesivamente.

Para mostrar el resto de información de la canción (nombre, autoría, etc.) se sigue un procedimiento similar, pero que en lugar de buscar una cifra busca esta información de nuevo en la hoja de puntos.

En el anexo 3 se puede apreciar una secuencia de imágenes de la interfaz que muestra cómo sería el uso en dos casos diferentes.

\section{Discusión}

Hemos visto a lo largo del trabajo las líneas principales que están en la base de esta herramienta. Se ha plasmado una descripción detallada y el funcionamiento de esta en lo que entendemos como un modelo de cómo habría de funcionar y con una propuesta de tratamiento de los textos.

El etiquetado ha sido quizás el aspecto que más problemas ha planteado y que ha exigido más reflexión. El cálculo de las frecuencias relativas, y el posterior cálculo de promedio y representatividad teniendo en cuenta sólo los tipos, y no las ocurrencias, ha resultado ser la opción más razonable, sobre todo si se superponen más de un filtro. No obstante, no tiene por qué ser la mejor opción y de cara a un desarrollo más elaborado de la herramienta podría replantearse esta cuestión.

Teniendo en cuenta la posible mejora del tratamiento de los textos y el cálculo que se realiza con la distinción entre tipos y ocurrencias, el funcionamiento de la herramienta ha resultado apropiado según las ideas que planteábamos al principio.

Consideramos que la herramienta demuestra ser fácil de usar y no se necesita ningún conocimiento previo, ya que está pensada a partir de las aplicaciones más comunes de música en streaming. De esta manera, fomenta el uso el uso de canciones, tanto en clase como fuera del aula en el marco del aprendizaje autónomo, y facilita y motiva la integración de los alumnos en la cultura meta.

Asimismo, entendemos que el objetivo de aportar variedad a la tipología musical usada en el aula de ELE se cumple, dado que hay un total de ciento ochenta y nueve textos sistematizados, vinculados a un total de treinta y dos combinaciones de diferentes géneros musicales, cubriendo todo el sistema verbal del español.

En referencia a sus limitaciones, como ya hemos visto, esta hoja de cálculo constituye solo un modelo. El número de textos analizados también es menor al que, en nuestra opinión, constituiría una herramienta más elaborada. Cuantas más canciones, más variedad y más posibilidades para trabajar con ellas. Todas las ventajas de la propuesta se verían potenciadas.

Otro aspecto sobre el que reflexionar es hasta qué punto se tienen en cuenta los sílabos. En este modelo solo se analiza el sistema verbal, sin embargo, hay muchas más posibilidades. En cuanto a gramática, se podrían analizar relaciones morfosintácticas; en cuanto a léxico, colocaciones y diferentes campos léxicos. De la misma manera, teniendo en cuenta descriptores nocio-funcionales, las canciones podrían contar con etiquetas de diferentes funciones y nociones representadas en las letras.

En el aspecto técnico, esta hoja de cálculo acierta en representar el modelo propuesto y es también operativa para su uso real. No obstante, un desarrollo posterior requeriría una programación más técnica que permitiese su uso en ordenadores y dispositivos 
móviles que no dependiese de un programa de hojas de cálculo, facilitando este en gran medida y haciendo la herramienta más liviana.

En resumen, nos sentimos satisfechos con lo conseguido hasta ahora y tenemos en cuenta las actuales limitaciones como metas a superar en un futuro.

\section{Referencias}

Alonso Pérez Ávila, E. (2007). El corpus lingüístico en la didáctica del léxico del español como LE. Boletín ASELE 37, 11-26 Disponible en: http://www.mecd.gob.es/educacion/mc/redele/bibliotecavirtual/numerosanteriores/2010/memoriamaster/1-trimestre/elenaalonso.html

Besson, M., Chobert, J. (2013). Musical Expertise and Second Language Learning. Brain Science 3, 923-940. Disponible en: https://www.ncbi.nlm.nih.gov/pmc/articles/PMC4061852/

Coronado González, M. L., García González, J. (1994) De cómo usar canciones en el aula, en Actas del Segundo Congreso Nacional de ASELE: español para extranjeros: didáctica e investigación. Madrid, del 3 al 5 de diciembre de 1990, 227-234. Disponible en: https://cvc.cervantes.es/ensenanza/biblioteca_ele/asele/pdf/02/02_0225.pdf

Fernández Martín, P. (2013). El papel de las canciones en la enseñanza de idioma a inmigrantes. Una propuesta didáctica. Marcoele 13. Disponible en: https://marcoele.com/descargas/17/fernandez-canciones_inmigrantes.pdf

Las Heras Calvo, M., Sáenz Hernández, M., y Serrano Romero, T. (2015). Sobre el uso de las canciones en el aula de ELE: sintonizando con los alumnos y afinando contenidos. En Morimoto, Y., Pavón Lucero, Mํ V., y Santamaría Martínez, R. (eds.) La enseñanza de ELE centrada en el alumno. XXV Congreso Internacional ASELE, Madrid, 1135-1144. Disponible https://cvc.cervantes.es/ensenanza/biblioteca_ele/asele/pdf/25/25_1135.pdf

López García, M.P., (2014). Aplicaciones de los corpus orales a la didáctica de ELE. Repertorios léxicos y contextos pragmalingüísticos. En Contreras Izquierdo, N.M. (ed.), La enseñanza del Español como LE/L2 en el siglo XXI. XXIV Congreso Internacional Asele, Málaga. 385-386. Disponible https://cvc.cervantes.es/ensenanza/biblioteca ele/asele/pdf/24/24 397.pdf

Murphey, T. (1992). Music and song. Oxford: Oxford University Press

Prieto, B. (2017). La música como recurso didáctico en la clase de ELE. Journal Of Tsuda College, 43, 131-140

Recksi, J.L., (2006). Corpus linguistics at the service of English teachers. Literatura y Lingüística 17, 303-324. Disponible en: https://scielo.conicyt.cl/scielo.php?script=sci_arttext\&pid=S0716-58112006000100017

Rodríguez López, B. (2005). Las canciones en la clase de español como lengua extranjera. En Álvarez, A., De la Hoz, C., Barrientos, L., Iglesias, I., Brafia, M., Martínez, P., Coto, V., Prieto, M., Cuevas, M. y Turza, A., (eds.) La Competencia Pragmática o la Enseñanza del Español como Lengua Extranjera. XVI Congreso Internacional de la ASELE La Competencia Pragmática o la Enseñanza del Español como Lengua Extranjera, Oviedo, 806-816. Disponible en: https://cvc.cervantes.es/ensenanza/biblioteca_ele/asele/asele_xvi.htm 


\section{Anexn I}

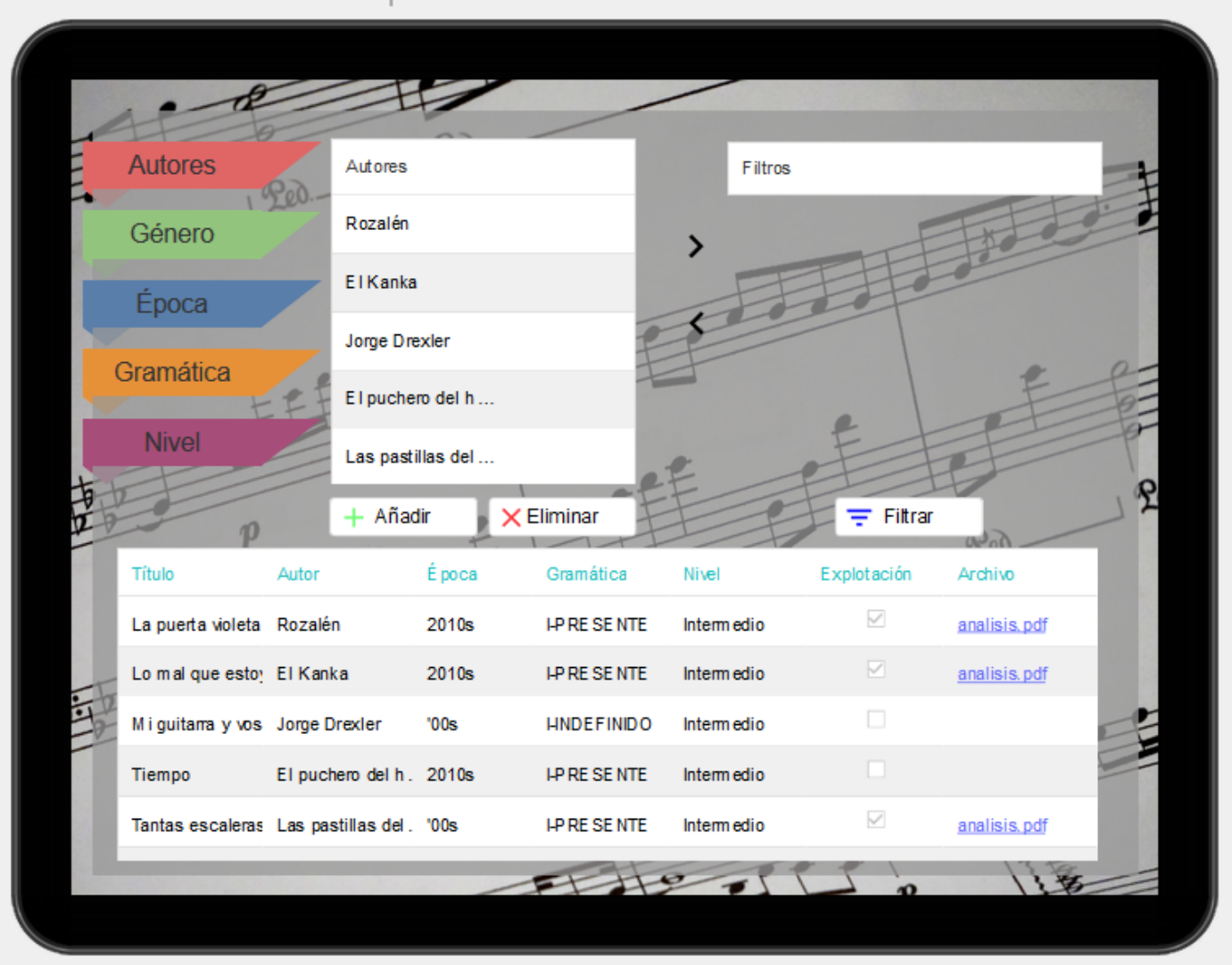

\section{Anexo II}

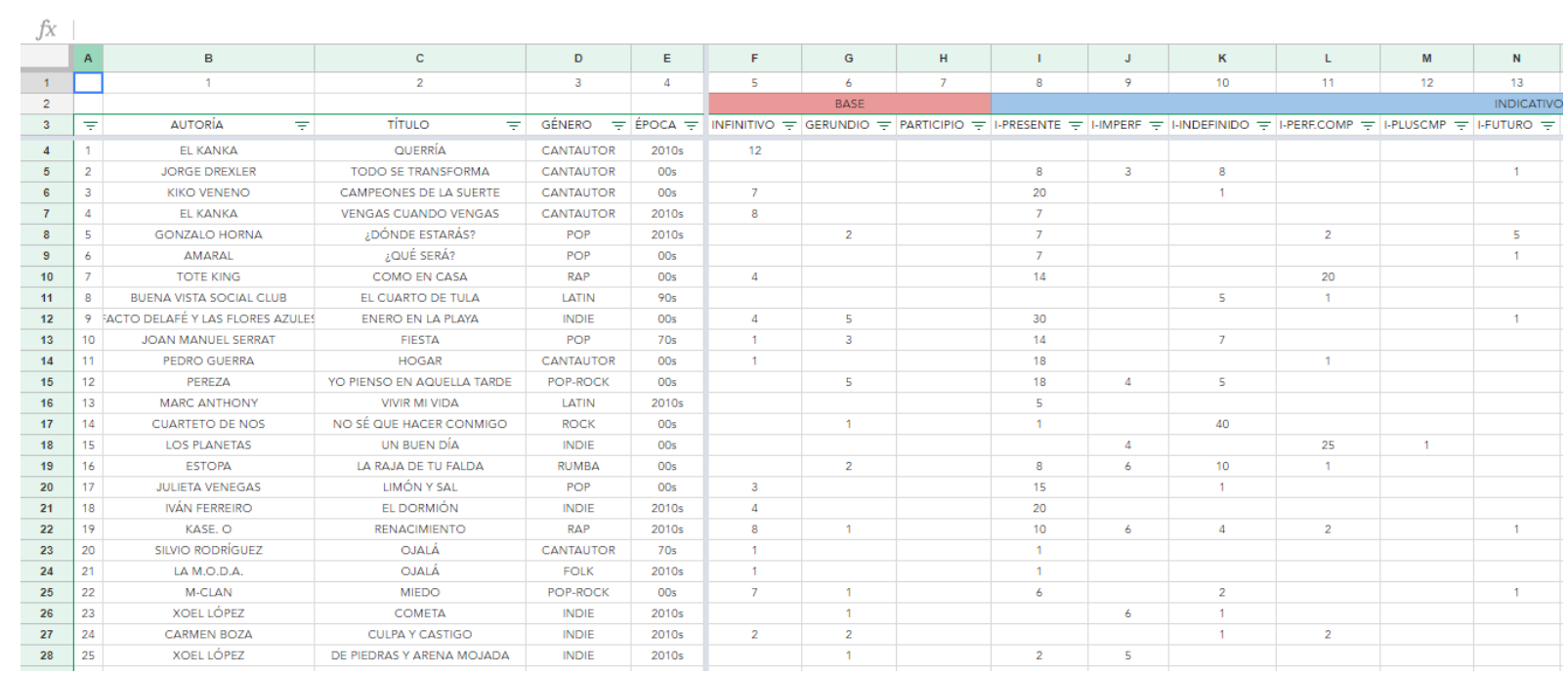




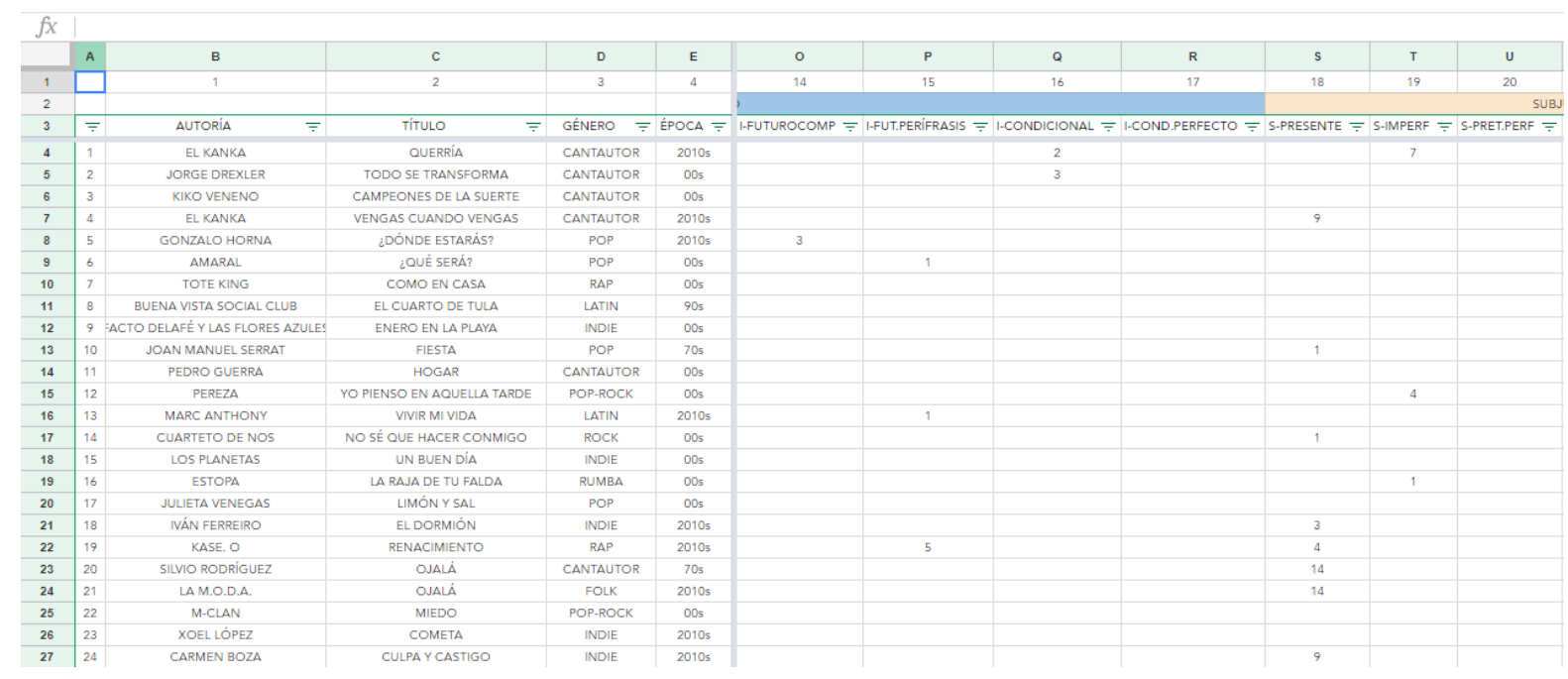

\begin{tabular}{|c|c|c|c|c|c|c|c|c|c|c|}
\hline & A & B & c & D & E & w & $\mathrm{x}$ & Y & $z$ & AA \\
\hline 1 & 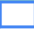 & 1 & 2 & 3 & 4 & 22 & 23 & 24 & 25 & \\
\hline 2 & & & & & & & & & IMPERATIVO & \\
\hline 3 & $\bar{F}$ & AUTORIA & Título & GÉNERO & ÉPOCA $=$ & S-FUTURO $=$ & S-FUTUROPERF - & $\bar{F}$ MPERATIVO $P \overline{-}$ & IMPERATIVO $=$ & NIVEL \\
\hline 4 & 1 & EL KANKA & QUERRIA & CANTAUTOR & 2010 s & & & & & INTERMEDIO \\
\hline 5 & 2 & JORGE DREXLER & TODO SE TRANSFORMA & CANTAUTOR & $00 \mathrm{~s}$ & & & & & INTERMEDIO \\
\hline 6 & 3 & KIKO VENENO & CAMPEONES DE LA SUERTE & CANTAUTOR & $00 \mathrm{~s}$ & & & & & INICIAL \\
\hline 7 & 4 & EL KANKA & VENGAS CUANDO VENGAS & CANTAUTOR & $2010 \mathrm{~s}$ & & & & 8 & INTERMEDIO \\
\hline 8 & 5 & GONZALO HORNA & ¿DÓNDE ESTARÁS? & POP & $2010 \mathrm{~s}$ & & & & & INTERMEDIO \\
\hline 9 & 6 & AMARAL & ¿QUÉ SERÁ? & POP & $00 \mathrm{~s}$ & & & & & INTERMEDIO \\
\hline 10 & 7 & TOTE KING & COMO EN CASA & RAP & 005 & & & 1 & 3 & INICIAL \\
\hline 11 & 8 & BUENA VISTA SOCIAL CLUB & EL CUARTO DE TULA & LATIN & 905 & & & & & INTERMEDIO \\
\hline 12 & 9 & ACTO DELAFÉ Y LAS FLORES AZULES & ENERO EN LA PLAYA & INDIE & $00 \mathrm{~s}$ & & & & & INTERMEDIO \\
\hline 13 & 10 & JOAN MANUEL SERRAT & FIESTA & POP & $70 \mathrm{~s}$ & & & & 1 & INICIAL \\
\hline 14 & 11 & PEDRO GUERRA & HOGAR & CANTAUTOR & $00 \mathrm{~s}$ & & & & & AVANZADO \\
\hline 15 & 12 & PEREZA & YO PIENSO EN AQUELLA TARDE & POP-ROCK & $00 \mathrm{~s}$ & & & & & INTERMEDIO \\
\hline 16 & 13 & MARC ANTHONY & VIVIR MI VIDA & LATIN & $2010 \mathrm{~s}$ & & & & & INICIAL \\
\hline 17 & 14 & CUARTETO DE NOS & NO SÉ QUE HACER CONMIGO & ROCK & 005 & & & & & INICIAL \\
\hline 18 & 15 & LOS PLANETAS & UN BUEN DIAA & INDIE & $00 \mathrm{~s}$ & & & & & INICIAL-INTERMEDIO \\
\hline 19 & 16 & ESTOPA & LA RAJA DE TU FALDA & RUMBA & $00 \mathrm{~s}$ & & & & & INTERMEDIO \\
\hline 20 & 17 & JULIETA VENEGAS & LIMÓN Y SAL & POP & $00 \mathrm{~s}$ & & & & & INICIAL \\
\hline 21 & 18 & IVÁN FERREIRO & EL DORMIÓN & INDIE & $2010 \mathrm{~s}$ & & & & & INTREMEDIO \\
\hline 22 & 19 & KASE. O & RENACIMIENTO & RAP & $2010 \mathrm{~s}$ & & & & 4 & NTERMEDIO-AVANZADO \\
\hline 23 & 20 & SILVIO RODRIGUEZ & OJAL̇ & CANTAUTOR & $70 \mathrm{~s}$ & & & & & INTERMEDIO-AVANZADC \\
\hline 24 & 21 & LAM.O.D.A. & OJALÁ & FOLK & 20105 & & & & & INTERMEDIO-AVANZADO \\
\hline 25 & 22 & M-CLAN & MIEDO & POP-ROCK & 005 & & & & & \begin{tabular}{|l|} 
INTERMEDIO \\
\end{tabular} \\
\hline 26 & 23 & XOEL LÓPEZ & COMETA & INDIE & $2010 \mathrm{~s}$ & & & & & INICIAL-INTERMEDIO \\
\hline 27 & 24 & CARMEN BOZA & CULPAY YASTIGO & INDIE & $2010 \mathrm{~s}$ & & & & & INTERMEDIO \\
\hline
\end{tabular}

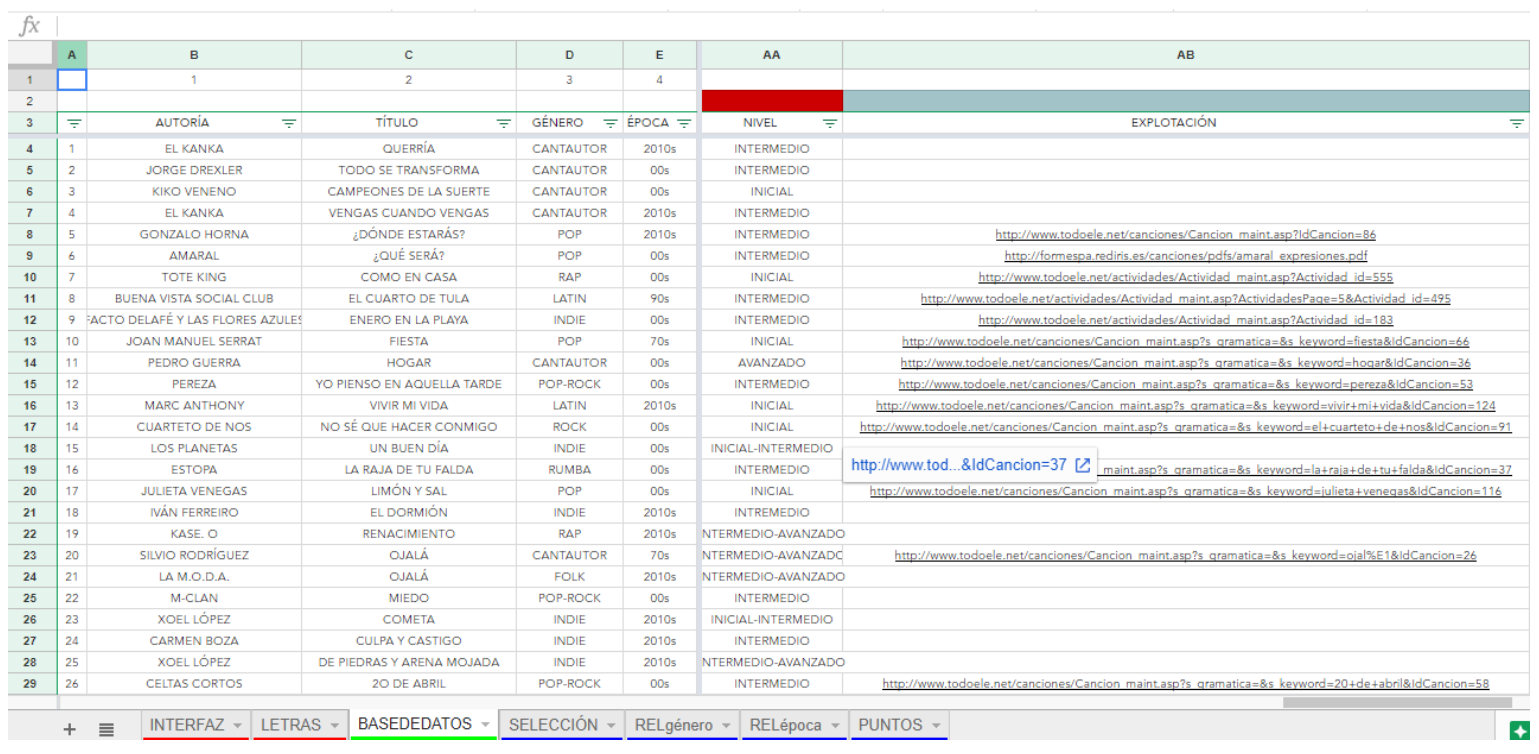




\begin{tabular}{|c|c|c|c|c|c|c|c|c|c|c|}
\hline \multicolumn{11}{|l|}{$f x$} \\
\hline & A & B & c & D & E & AC & $A D$ & AE & AF & AG \\
\hline 1 & & 1 & 2 & 3 & 4 & & & & & \\
\hline 2 & & & & & & & & & & \\
\hline 4 & 1 & EL KANKA & QUERRIAA & CANTAUTOR & 2010 s & & & & & \\
\hline 5 & 2 & JORGE DREXLER & TODO SE TRANSFORMA & CANTAUTOR & 005 & & & & & \\
\hline 6 & 3 & KIKO VENENO & CAMPEONES DE LA SUERTE & CANTAUTOR & $00 \mathrm{~s}$ & & & & & \\
\hline 9 & 6 & AMARAL & ¿QUÉ SERÁ? & POP & $00 \mathrm{~s}$ & & & & & \\
\hline 10 & 7 & TOTE KING & COMO EN CASA & RAP & 005 & & & & & \\
\hline 11 & 8 & BUENA VISTA SOCIAL CLUB & EL CUARTO DE TULA & LATIN & 905 & & & & & \\
\hline 12 & 9 & :ACTO DELAFÉ Y LAS FLORES AZULES & ENERO EN LA PLAYA & INDIE & 00 s & & & & & \\
\hline 13 & 10 & JOAN MANUEL SERRAT & FIESTA & POP & 705 & & & & & \\
\hline 14 & 11 & PEDRO GUERRA & HOGAR & CANTAUTOR & 00 s & & & & & \\
\hline 19 & 16 & ESTOPA & LA RAJA DE TU FALDA & RUMBA & 005 & & & & & \\
\hline 20 & 17 & JULIETA VENEGAS & LIMÓN Y SAL & POP & 005 & & & & & \\
\hline 21 & 18 & IVÁN FERREIRO & EL DORMIÓN & INDIE & $2010 \mathrm{~s}$ & & & & & \\
\hline 22 & 19 & KASE. $O$ & RENACIMIENTO & RAP & 20105 & & & & & \\
\hline 23 & 20 & SILVIO RODRIGUEZ & OJALÁ & CANTAUTOR & $70 s$ & & & & & \\
\hline 24 & 21 & LA M.O.D.A. & OJALÁ & FOLK & $2010 \mathrm{~s}$ & & & & & \\
\hline 25 & 22 & M-CLAN & MIEDO & POP-ROCK & 005 & & & & & \\
\hline 26 & 23 & XOEL LÓPEZ & COMETA & INDIE & $2010 \mathrm{~s}$ & & & & & \\
\hline 27 & 24 & CARMEN BOZA & CULPA Y CASTIGO & INDIE & $2010 \mathrm{~s}$ & & & & & \\
\hline
\end{tabular}

\section{Anexo III}

Aquí podemos ver las canciones que nos propondría la herramienta al seleccionar "flamenco", "I-presente" (presente de indicativo) y "S-presente" (presente de subjuntivo)

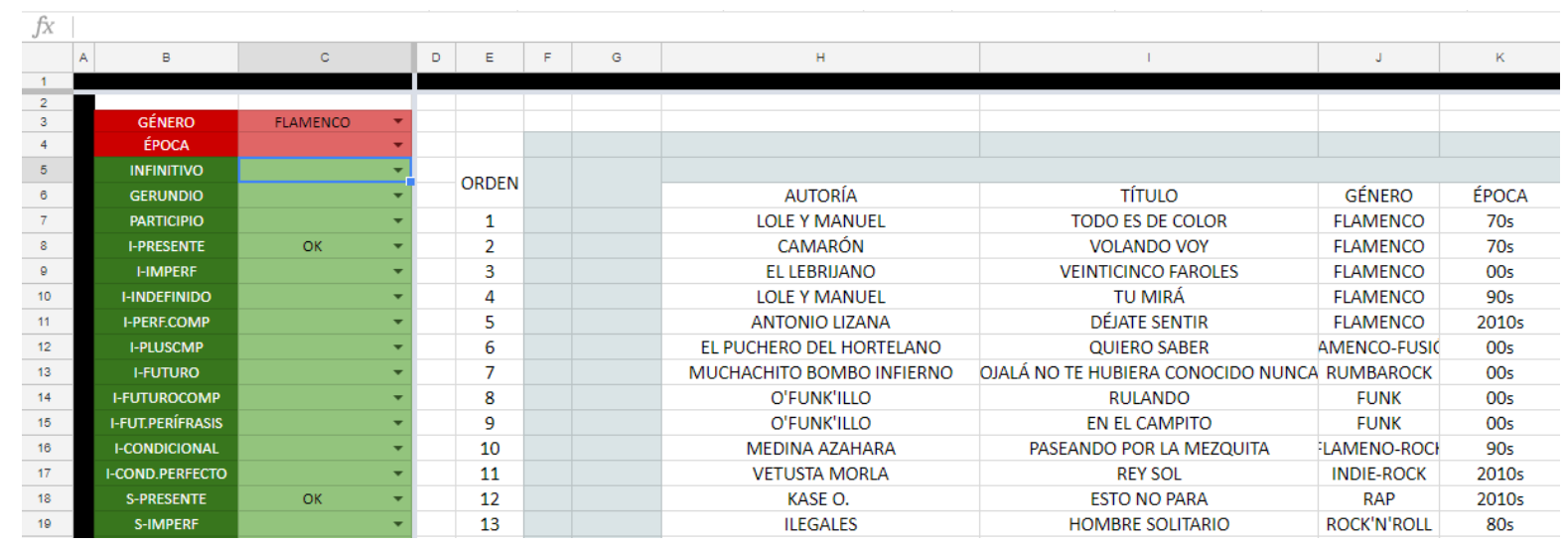

Al añadir otro filtro, en este caso "infinitivo", el cálculo cambia y provoca que esta vez la canción Veinticinco faroles de El Lebrijano aparezca más arriba en la lista. 


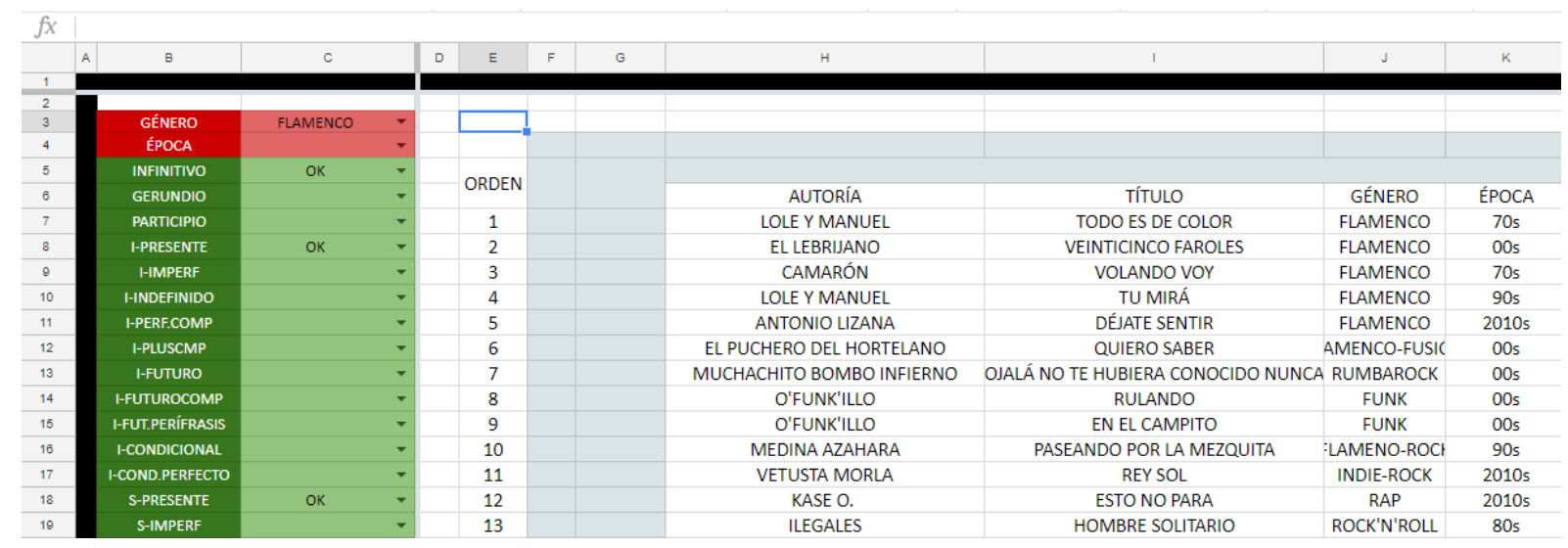

Si quisiéramos trabajar, por ejemplo, las perífrasis que incluyan presente y gerundio, y hemos decidido que el género que queremos es el rock, estas serían las recomendaciones.

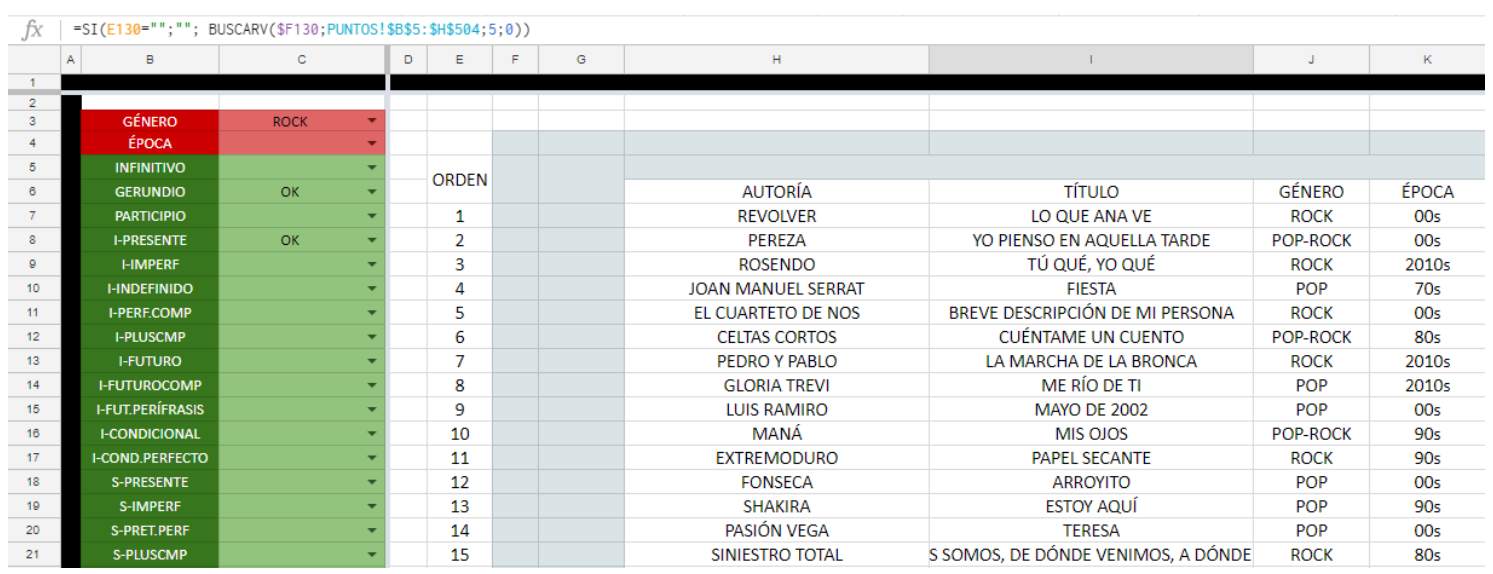

